\title{
Personal Tribute to Jacob Neufeld
}

Dear Dr. Clayton and the Pediatric Rehabilitation Medicine Community:

You knew the man, Jacob Alan Neufeld, as a professional and colleague, but we'd like to share some of his personal history with you in addition.

Born in 1962, Dr. Jay Neufeld was the son of Janet and the late Eugene Neufeld. In high school, he was a Junior Rotarian, became an Eagle Scout Bronze Palm, and met his future wife Wendy Hood. In college, Jay received a Rotary International Fellowship and studied in Israel. He also traveled to India. At the age of 23, as a Rotarian, he presented the idea of "Strike Out Hunger" to Dave Montgomery, the President of the Philadelphia Phillies. Strike Out Hunger is still going strong 33 years later and has benefitted local food banks as well as Rotary's Polio Plus Program, which has nearly eradicated polio in developing countries. For every $\$ 30$ ticket sold, the Phillies gave back $\$ 10$ to Rotary and the Bill Gates Foundation donated \$20. As a young man, Jay had the vision to recognize a local and international need and the ingenuity to create a program that would last indefinitely.
Dr. Neufeld's unsurpassed compassion for humanity and call to act were evidenced most clearly by his work following the tragic events of September 11, 2001. While at The Rusk Institute, he took time off from his busy clinic and academic schedule to work at the triage center with first responders and the victims and families. It was not something he had trained to do in medical school. He did it because he was "Dr. J".

During the latter portion of his career, Dr. Neufeld discovered additional talent and vision in the world of medical art and painting. He began putting color on canvas, not painting with brushes, but utilizing expired medical equipment and devices such as old surgical tools, clamps, catheter tubes, sponges, and syringes. It was a form of art and beauty not yet witnessed by the artistic world. Dr. J's artwork is displayed in Boise, Idaho in places such as the foyer of Ballet Idaho. It is our ongoing hope that Dr. J continues to enjoy his painting and other passions in the pursuit of excellence across the canvas of eternity.

Kevin P. Murphy MD, Duluth, MN Elaine Pico MD, Oakland, CA 